\title{
Mechanical properties and deformation mechanisms in microscale Ti-55531 alloy
}

\author{
Wenjuan Kou, Qiaoyan Sun*, Lin Xiao*, Jun Sun
}

State Key Laboratory for Mechanical Behavior of Materials, Xi'an Jiaotong University, Xi'an, Shaanxi 710049, P. R. China

* Corresponding authors.

E-mail address: qysun@mail.xjtu.edu.cn (Qiaoyan Sun), Ixiao@mail.xjtu.edu.cn (Lin Xiao).

\begin{abstract}
:
The mechanical behaviors and deformation mechanisms of solution treated and $450^{\circ} \mathrm{C}$ aged Ti-55531 alloy microsamples are investigated by the micro-compression and micro-bending. The results show that the dislocation slip is a concentrated movement in the solution treated microsamples which containing nanoscale $\omega$ phase. Under the tensile and compressive stress, there were serious strain bursts occurred in the plastic deformation of solution treated microsamples. But the dislocation slip is transmit at the phase interface in the $450^{\circ} \mathrm{C}$ aged microsamples which containing high density of a phase. The deformation behavior exhibits high strength and excellent stability in the micro-compression and micro-bending process. The different mechanical behaviors and deformation mechanisms of Ti-55531 alloy containing different second phase have significant guidance for tailoring the microstructure and mechanical properties.
\end{abstract}

Key words: Titanium, Micro-compression, Micro-bending, Dislocation, Mechanical behavior

\section{Introduction}

Precipitation strengthening is one of the most effective approach for the enhancement of metallic alloy strength, including solid-solution strengthening, grain-boundary strengthening, and work hardening [1,2]. A fine distribution of precipitates can impede dislocation motion which strengthens the alloy directly. In order to meet the service-performance requirements, including mechanical strength, corrosion-and oxidation-resistant properties, etc., several solute elements are generally added to alloy or minor-alloy the solvent matrix constituted of one or two primary elements in conventional engineering structural materials [3,4]. Most of high-performance metallic materials, including Al alloys, Mg alloys, stainless steels, and Ni superalloys, all contain a uniform microstructure of diverse second-phase particles distributed in their solid-solution matrix [5-9]. For example, Mg-11Li-3Al alloy with several traditional Mg alloys exhibit not only a higher strength, but also a much better ductility with an elongation to fracture of about $27 \%$, which is attributed to the coherent precipitation of spherical L21 nanoparticles with a particle size of 2 20 nm [10]. On the other hand, recent studies of magnesium alloys have shown that nano-precipitates and micro-precipitates can act as sites and paths for void nucleation, crack initiation and subsequent crack propagation during spall failure [11]. In single-crystal Ni-based superalloys, the coherent precipitation of cuboidal $\mathrm{L}_{2} \mathrm{\gamma}^{\prime} \gamma^{\prime}$ particles are responsible for the necessary strength at much higher temperatures near to the melting point $[12,13]$. The Al-Cu binary system is a well-studied 
precipitation-strengthening system, since it forms the basis for many types of age-hardening alloys with technological importance [14]. The precipitation strengthening mechanisms can be divided into two categories, the dislocation shearing mechanism and the Orowan dislocation bypassing mechanism, depending on the interaction between moving dislocations and precipitates. The dislocation-shearing mechanism is generally active when the precipitates are coherent with the matrix, and the particle size is small, while the Orowan bypassing mechanism dominates when the coherent particle size exceeds a critical value or when the particles are incoherent with the matrix $[4,15,16]$.

Titanium alloys are considered as attractive materials due to their high strength-to-weight ratio, and abundant phase transition process under different heat treatment conditions. Their mechanical properties are strongly dependent on the microstructural characteristics, especially the volume fraction, the morphology and the distribution of the second phase [17-20], therefore the second phase in $\beta$ matrix has been a topic of intensive studies. It is worth noticing that the properties of the $\beta$-Ti alloys are almost tested from the polycrystalline bulk materials, and the effect of grain boundaries cannot be ignored. As we known, grain boundaries have significate effect on the mechanical properties of the metals [21-23]. Precise mechanistic analysis using nanoindentation becomes widely used to investigate the local area deformation characters [24,25]. Therefore, the microsamples test was adopted to isolating individual microstructural units and selecting particular slip systems for investigation. In this study, the solution treated and the $450^{\circ} \mathrm{C}$ aged Ti-55531 alloy were chosen as the object to investigate the deformation mechanisms and the interaction details between dislocations and different second phases under uniaxial compression and bending.

\section{Methods}

Polycrystalline Ti-5wt\%Al-5wt\%Mo-5wt\%V-3wt\%Cr-1wt\%Zr (Ti-55531) bulk samples with $4 \mathrm{~mm}$ ' 4 mm in cross section and 7 $\mathrm{mm}$ in length, were solution heat-treated at $950^{\circ} \mathrm{C}$ for $24 \mathrm{~h}$ in a high vacuum furnace followed by water quench. One of the bulks needed a further isothermal vacuum annealing, performed at $300^{\circ} \mathrm{C}$ for $20 \mathrm{~h}$ to form a large number of athermal $\omega$ precipitates[26-28]. The annealing temperature was further increased to $450^{\circ} \mathrm{C}$ for $15 \mathrm{~h}$ to dissolute the remained $\omega$ and promote the growth of a precipitates [27]. The $300^{\circ} \mathrm{C}$ treatment and the $450^{\circ} \mathrm{C}$ treatment are associated with the ageing treatment.

The square bulks were mechanically and electrochemically polished before fabricating into pillars. For both of the Ti-55531 alloy bulks, grains oriented to $<101>\beta$ were selected to fabricate micro-cantilevers. A group of single-crystal micropillars were fabricated using the FEI Helios operated at an ion beam voltage of $30 \mathrm{kV}$ with a variety of currents. Micropillar diameter, ranges from $300 \mathrm{~nm}$ to $3 \mu \mathrm{m}$, with an aspect ratio of $\sim 2.5$. The taper of the micropillars is between $2^{\circ}$ and $4^{\circ}$. Three to five samples

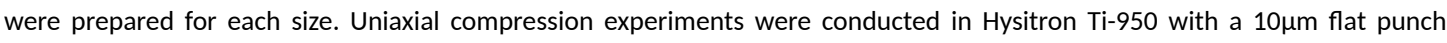
diamond tip at a constant nominal strain rate of $1 \times 10^{-3} \mathrm{~s}^{-1}$. A group of micro-cantilevers were fabricated using the FEI Helios Dual Beam Focus Ion Beam (FIB) microscope operated at an ion beam voltage of $30 \mathrm{kV}$ with a variety of currents. The dimensions of all cantilevers are $15 \mu \mathrm{m}$ long and $2.5 \mu \mathrm{m}$ wide with an equilateral triangular cross-section. Three to five samples were prepared for each size. Micro-bending tests were performed in the Hysitron T1950 nanoindentation, at a nominal axial strain rate of $1 \times 10^{-3} \mathrm{~s}^{-1}$ at the bottom apex of the cantilever at its built-in end [29]. The micro-cantilever sample was deflected to $3 \mu \mathrm{m}$ at the load point, as indicated by the white arrow in the Fig. 1(b), The images of micropillar and micro-cantilever are shown in Fig.1. The post-compression morphology of the pillars was examined with scanning electron microscopy (SEM). 

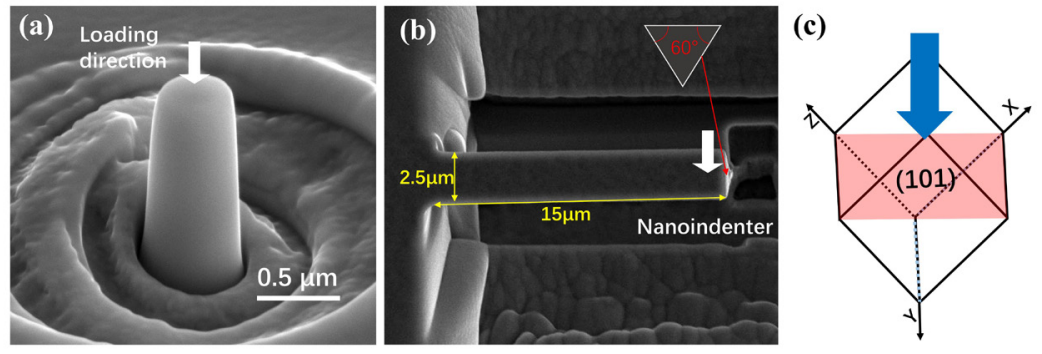

Fig. 1 (a) Typical SEM morphology of the micropillar (b) Typical SEM morphology of the micro-cantilever (c) loading direction of the micropillar and micro-cantilever.

\section{$\underline{\text { Results and discussion }}$}

Fig. 2 showed typical TEM microstructure of the undeformed solution-treated and $450^{\circ} \mathrm{C}$ aged Ti-55531 alloy, respectively. The selected area electron diffraction (SAED) pattern analysis along the $\langle 011\rangle_{\beta}$ zone axis of the $\beta$ matrix showed that the primary components in the solution-treated Ti-55531 alloy included the $\beta$ matrix and the $\omega$ phase, as shown in Fig. 2(a)-(b). Nanoscale $\omega$ phase homogeneously were distribute in the $\beta$ matrix. These $\omega$ phase were produced through athermal transformation from the $\beta$ to the $\omega$ during water quenching.

For the $450^{\circ} \mathrm{C}$ aged Ti-55531 alloy, high density of $\alpha$ phase were formed in the $\beta$ matrix. The size of $\alpha$ phase was $50-100 \mathrm{~nm}$, which was much larger than that of the $\omega$ phase. The $\alpha$ phase were short rod-like and distributed uniformly in the $\beta$ matrix, as shown in Fig. 2(c)-(d). The $\beta$ matrix had a common $\beta-\{110\}$ pole with $\alpha-\{0001\}$ pole. The $\alpha$ phase and the $\beta$ matrix have the following Burgers orientation relationship: $\{110\}_{\beta} / /\{0001\}_{\alpha}$ and $<1 \overline{1} 1>_{\beta} / /<11 \overline{2} 0>_{\alpha}$ [30-32], as shown in Fig. 2(e). 

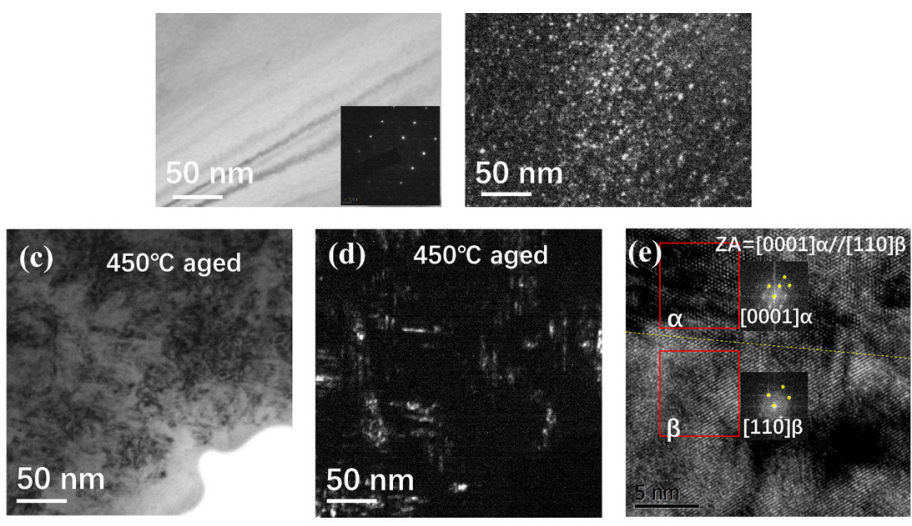

Fig. 2 Undeformed microstructures. (a) the bright-field image of the solution-treated Ti-55531 alloy (b) the dark-field image of the solution-treated Ti-55531 alloy, high density of the $\omega$ phase distributed in the $\beta$ matrix, (c) the bright-field image and (d) the dark-field image of the $450^{\circ} \mathrm{Caged}$ Ti-55531 alloy, fine $\alpha$ phase distributed in the $\beta$ matrix, (e) HRTEM image of $\beta / \alpha$ interface, following Burgers orientation relationship.

Typical stress-strain curves of the solution-treated and the $450^{\circ} \mathrm{C}$ aged Ti-55531 alloy micropillars with various diameters compressed along $<101\rangle_{\beta}$ orientation were shown in Fig. 3. The yield strength was defined as the flow stress of the micropillar at $0.2 \%$ engineering strain. For the $450{ }^{\circ} \mathrm{C}$ aged Ti-55531 alloy micropillars, the stress-strain curves were smooth and continuous, as shown in Fig. 3(a)-(b). The yield strength was about 2.3GPa, regardless of the pillar sizes. For the solution-treated Ti-55531 alloy micropillars, the strain bursts become more serious for smaller micropillars, as shown in Fig. 3(c)-(d). The relevant yield strength showing the "smaller is stronger" phenomenon. On a close examination, the stress-strain curves of the $450{ }^{\circ} \mathrm{C}$ aged micropillars showed a smooth and stable plastic deformation behavior, which was much similar with the bulk sample. So the $450^{\circ} \mathrm{C}$ aged Ti-55531 micropillars exhibited an excellent combination of high strength and stable plasticity. 

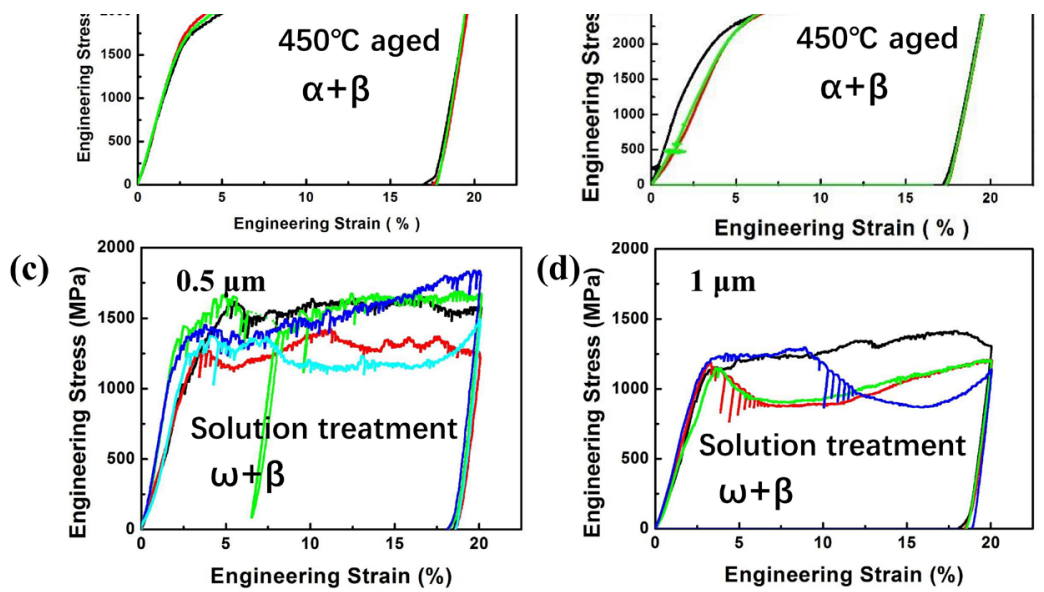

Fig. 3 The engineering stress-strain curves of the $450^{\circ} \mathrm{C}$ aged Ti-55531 alloy (a) $0.5 \mu \mathrm{m}$ and (b) $1 \mu \mathrm{m}$ micropillars, the engineering stressstrain curves of the solution-treated Ti-55531 alloy (c) $0.5 \mu \mathrm{m}$ and (d) $1 \mu \mathrm{m}$ micropillars.

Fig. 4 shows typical loading-displacement curves of the solution-treated and the $450^{\circ} \mathrm{C}$ aged Ti-55531 alloy micro-cantilevers. For the $450^{\circ} \mathrm{C}$ aged Ti-55531 alloy micro-cantilever, the loading curve was smooth and continuous, as shown in Fig. 4(a). For the solution-treated Ti-55531 alloy micro-cantilever, the bursts were obvious in the loading curve, as shown in Fig. 4(b). At the same time, the strength of the $450^{\circ} \mathrm{C}$ aged Ti-55531 alloy micro-cantilever was higher than that of the solution-treated Ti-55531 alloy micro-cantilever. Both the micropillar compression results and the micro-cantilever bending results show the excellent stability in plasticity of microscale $450^{\circ} \mathrm{C}$ aged Ti-55531 alloy. 

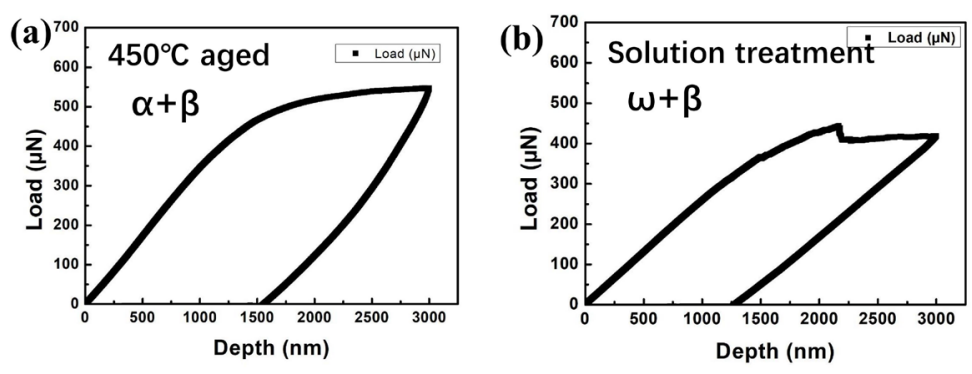

Fig. 4 Typical loading-displacement curves of (a) the $450^{\circ} \mathrm{Caged}$ and (b) the solution-treated Ti-55531 alloy micro-cantilevers.

Based on the compression curves and the bending curves of solution-treated and $450^{\circ} \mathrm{C}$ aged Ti-55531 alloy microscale samples, the samples containing high density of the a phase has a better combination of strength and plasticity than the samples containing high density of $\omega$ phase. The dislocation movement in the $450{ }^{\circ} \mathrm{C}$ aged samples was much more stable without strain bursts. However, the strain bursts in the curves of solution-treated samples indicated that the collection of dislocation movement existed localized in several slip planes. The collection of dislocation movement in the specific slip planes causes the unstability of plastic deformation.

Fig. 5 showed SEM images of the deformed solution-treated and $450^{\circ} \mathrm{C}$ aged Ti- 55531 alloy micropillars, respectively. For the $450^{\circ} \mathrm{C}$ aged Ti-55531 alloy micropillars, tortuous slip traces were observed on the surfaces instead of the significant slip steps in solution-treated micropillars, as shown in Fig. 5(a)-(b). At the same time, many fine slip steps were obvious on the sides of the micropillars of $450^{\circ} \mathrm{C}$ aged Ti-55531 alloy. The loading direction is along [101] orientation, and the Schmid factor of $\{112\}$ $\beta^{<111>\beta} \beta$ slip system is the biggest, calculated as 0.471 . Compared with the experimental results, $\{112\}_{\beta}<111>\beta$ slip system was activated in the $450^{\circ} \mathrm{C}$ aged Ti-55531 alloy micropillars.

A group of parallel slip bands and several large slip steps were observed on the surface of the solution-treated Ti-55531 alloy micropillar, as indicated by the white dashed lines in Fig. 5(c)-(d). On a close examination, only one slip system was activated in the solution-treated micropillars. The angle between the slip plane and the top surface of the pillar $\left(\{101\}_{\beta}\right)$ was $53^{\circ}$, which indicated that the $\{112\}_{\beta}<111>\beta$ slip system was activated in the solution-treated micropillars. 

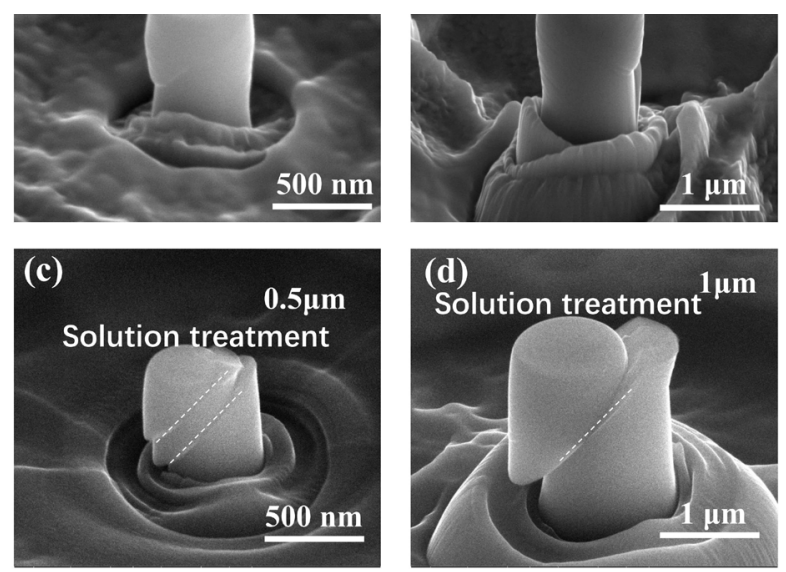

Fig. 5 SEM morphology of the deformed micropillars with different diameters (a)-(b) the deformed $450^{\circ} \mathrm{C}$ aged Ti-55531 alloy micropillars,

(c)-(d) the solution-treated deformed Ti-55531 alloy micropillars.

Fig. 6 show SEM images of the deformed solution-treated and $450^{\circ} \mathrm{C}$ aged Ti-55531 alloy micro-cantilevers. For the deformed solution-treated Ti-55531 alloy micro-cantilevers, there were obvious slip traces at the top and the bottom, as shown in Fig 6(b). All the slip steps were clear and straight. On a close examination, the micro-cracks can be observed near the top surface and the bursts in the loading curve is corresponding to the slip steps on the surface of the deformed cantilevers. The dislocation movement in the solution-treated samples was concentrated in local region. Since the interface between the nanoscale $\omega$ phase and the $\beta$ matrix was coherent [33], the dislocation would cut through the nanoscale $\omega$ phase. Once the $\omega$ phase was cut by the dislocation slip, the dislocation slip channel would be formed for further dislocation movement. So there were obvious slip steps on the surface of the solution-treated samples. The localized dislocation movement caused the stress concentration which induced the formation of microcracks on the top surface.

For the deformed $450^{\circ} \mathrm{C}$ aged Ti-55531 alloy micro-cantilevers, very tiny slip traces were observed on the surfaces of pillars rather than the significant slip steps observed in solution-treated micro-cantilevers. There were only a few slip traces at the top and the bottom, as shown in Fig 6(d). All the slip steps were zigzag. Different with the solution-treated samples, the deformation in the $450^{\circ} \mathrm{C}$ aged samples was homogeneous. The slip trace on the surface was mild and shallow. It had found that the interface between the $\alpha$ phase and $\beta$ matrix was semi-coherent and following the Burgers orientation relationship. Compared with the nanoscale $\omega$ phase, the size of a phase was much larger, and the dislocation can not directly cut through the $a$ phase. So the a phase had a significant effect on impeding the dislocation movement. On the other hand, the Burgers orientation relationship between the a phase and the $\beta$ matrix promoted the dislocation slip transmit at the interface. So the dislocation slip system could be activated in the a phase. The dislocation "slip relay" model had described in our previous work [34]. The model of dislocation movement was applicable under both compressive and tensile stress. Generally speaking, the nanoscale a phase formed in the ageing treatment is considered as hard particles in the bulk samples and can not deform in the plastic deformation, so the dislocation slip can not transfer across the interface easily. But in the microscale samples, the slip systems of 

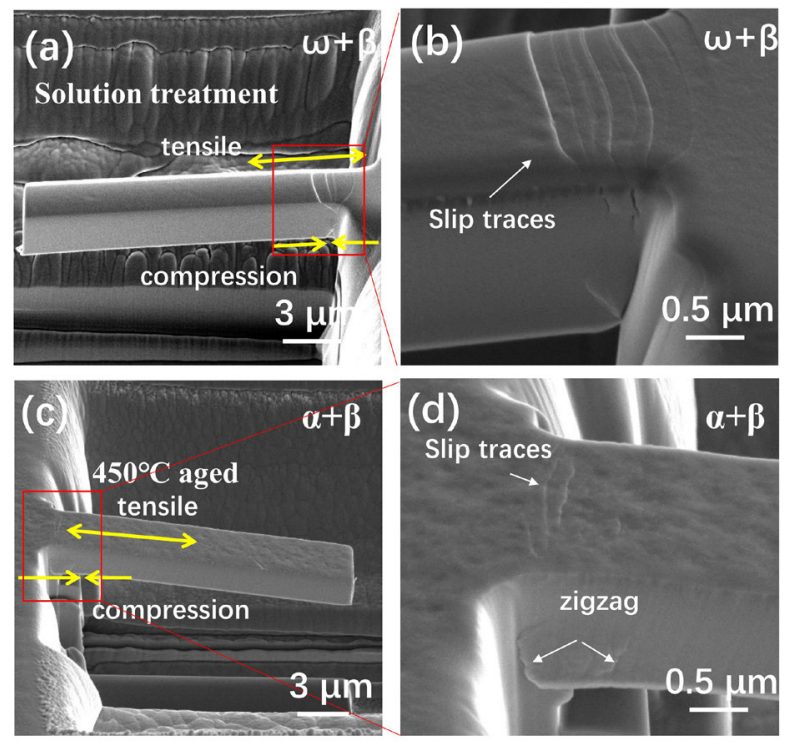

Fig. 6 SEM morphology of the deformed micro-cantilevers (a)-(b) the deformed solution-treated Ti-55531 alloy micro-cantilevers, (c)-(d) the deformed $450^{\circ} \mathrm{C}$ aged Ti-55531 alloy micro-cantilevers.

\section{Conclusion}

The results of micro-compression and micro-bending tests show the different mechanical behaviors and deformation mechanisms for solution treated and $450^{\circ} \mathrm{C}$ aged Ti- 55531 alloy samples. The dislocation slip is a concentrated movement in the solution treated microsamples which containing nanoscale $\omega$ phase. Under the tensile and compressive stress, the plastic deformation of the solution treated microsamples is unstable because the dislocations slip in localized area which causes strain bursts. While the dislocation slip is transmitted at the phase interface in the $450^{\circ} \mathrm{C}$ aged microsamples which containing high density of a phase. The deformation behavior exhibits high strength and excellent stability in plasticity in the micro-compression and micro-bending deformation.

\section{Acknowledgements}

The authors gratefully thank support from the National Natural Science Foundation of China (51671158, 51621063, 51471129), 973 Program of China (2014CB644003), and the 111 Project 2.0 (PB2018008). Wenjuan Kou would like to 


\section{$\underline{\text { References }}$}

[1] L.M. Brown, R.K. Ham, Dislocation-particle Interactions. In Strengthening Methods in Crystals, Eds. Elsevier, Amsterdam, The Netherlands (1971).

[2] C. S. Han, R.H. Wagoner, F. Barlat, Int. J. Plasticity 20 (2004) 477-494.

[3] G. Aggen, M. Allen, ASM Handbook Volume I, Properties and Selection: Irons, Steels, and High-Performance Alloys, The Materials Information Company, NY, USA (2018).

[4] K. Huang, K. Marthinsen, Q. Zhao, R.E. Logé, Prog. Mater. Sci. 92 (2018) 284-359.

[5] B. Yang, Y.T. Zhou, D. Chen, X. L. Ma, Sci. Rep. 3 (2013) 1039.

[6] P. Zhang, O.U. Salman, J. Zhang, G. Liu, J. Weiss, L. Truskinovsky, J. Sun, Acta Mater. 128 (2017) 351-364.

[7] G. Wu, K. Chan, L. Zhu, L. Sun, J. Lu, Nature (2017) 21691.

[8]Y. Yamamoto, M.P. Brady, Z.P. Lu, P.J. Maziasz, C.T. Liu, B.A. Pint, K.L. More, H.M. Meyer, E.A. Payzant, Science 316 (2007) 433436.

[9] B. Girault, A.S. Schneider, C.P. Frick, E. Arzt, Adv. Eng. Mater. 12(2010) 385-388.

[10] W.Q. Xu, N. Birbilis, G. Sha, Y. Wang, J.E. Daniels, Y. Xiao, M. Ferry, Nature 14(2015) 1229-1236.

[11] L. Farbaniec, C.L. Williams, L. Kecskes, K.T. Ramesh, R. Becker, Int. J Impact Eng. 98 (2016) 34-41.

[12] Q. Ding, S. Li, L. Chen, X. Han, Z. Zhang, Q. Yu, J. Li, Acta Mater. 154 (2018) 137-146.

[13] J.X. Zhang, J.C. Wang, H. Harada, Y. Koizumi, Acta Mater. 53 (2005) 4623-4633.

[14] F.W. Gayle, M. Goodway, Science 266(1994) 1015-1507.

[15] D.N. Seidman, E.A. Marquis, D.C. Dunand, Acta Mater. 50 (2002) 4021-4035.

[16] D.J. Bacon, U.F. Kocks, R.O. Scattergood, Philos. Mag. 28 (1973) 1241-1263.

[17] C.M. Liu, X.J. Tian, H.B. Tang, H.M. Wang, J Alloys Compd. 572 (2013) 17-24.

[17] N.G. Jones, R.J. Dashwood, D. Dye, M. Jackson, Mater. Sci. Eng. A 490 (2008) 369-377.

[19] M. Salib, J. Teixeira, L. Germain, E. Lamielle, N. Gey, E. Aeby-Gautier, Acta Mater. 61 (2013) 3758-3768.

[20] K Hua, Y. Zhang, H. Kou, J. Li, W. Gan, J.J. Fundenberger, C. Esling, Acta Mater. 132 (2017) 307-326.

[21] J. Kacher, B.P. Eftink, B. Cui, I.M. Robertson, Curr. Opin. Solid St M 18 (2014) 227-243. 
[24] T. Jun, Z. Zhang, G. Sernicola, F. P.E. Dunne, T. B. Britton, Acta Mater. 107 (2016) 298-309.

[25] T. Jun, G. Sernicola, F. P.E. Dunne, T. Be. Britton, Mater. Sci. Eng. A 649 (2016) 39-47.

[26] Y.F. Zheng, R.E.A. Williams, J.M. Sosa, T. Alam, Y. Wang, R. Banerjee, H.L. Fraser, Acta Mater. 103(2016) 165-173.

[27] S. Nag, R. Banerjee, R. Srinivasan, J.Y. Hwang, M. Harper, H.L. Fraser, Acta Mater. 57(2009) 2136-2147.

[28] T. Li, D. Kent, G. Sha, L.T. Stephenson, A.V. Ceguerra, S.P. Ringer, M.S. Dargusch, J. M. Cairney, Acta Mater. 106 (2016) 353366.

[29] R. Ding , J. Gong , A. J. Wilkinson, I. P. Jones, Philos. Mag. 92(2012) 3290-3314.

[30] W. G. Burgers, Physica. 1(1934) 561-586.

[31] S.M.C .Bohemen, A.Kamp, R.H. Petrov, L.A.I. Kestens, J. Sietsma, Acta Mater. 56 (2008) 5907-5914.

[32] T. Furuhara, H.Nakamori, T. Maki, Mater. Trans. JIM. 33(1992) 585-595.

[33] M.J. Lai, C.C. Tasan, J. Zhang, B. Grabowski, L.F. Huang, D. Raabe, Acta Mater. 92 (2015) 55-63.

[34] W. Kou, Q. Sun, L. Xiao. J. Sun, Sci. Rep. 9 (2019) 5075. 